\title{
Niat Investasi Generasi Milenial Di Pasar Modal
}

\author{
Vania Onasie dan Sawidji Widoatmodjo \\ Program Studi Manajemen Fakultas Ekonomi dan Bisnis \\ Universitas Tarumanagara, Jakarta \\ Email:vaniaonasie@yahoo.co.id
}

\begin{abstract}
The purpose of this research is to examine whether 1) financial attitudes can affect investment intention; 2) risk aversion can affect investment intention; 3) locus of control can affect investment intention. Sample was collected by purposive sampling method with total amount 190 respondents in Faculty Economic and Business at Tarumanagara University and analyzed with SmartPLS 3.2.8. The result of this study show that financial attitudes, risk aversion and locus of control have significant effect to investment intention.
\end{abstract}

Keywords: Financial Attitudes, Risk Aversion, Locus of Control, Investment Intention

\begin{abstract}
Abstrak: Tujuan atas penelitian ini adalah untuk menganalisis apakah 1) sikap keuangan dapat mempengaruhi niat investasi; 2) sikap menghindari risiko dapat mempengaruhi niat investasi; 3) lokus kendali dapat mempengaruhi niat investasi. Sampel diperoleh dengan metode purposive sampling dengan total 190 responden di Fakultas Ekonomi dan Bisnis Universitas Tarumanagara dan dianalisa dengan SmartPLS 3.2.8. Hasil penelitian ini menunjukkan bahwa sikap keuangan, sikap menghindari risiko, dan lokus kendali memiliki pengaruh signifikan terhadap niat investasi.
\end{abstract}

Kata Kunci: Sikap keuangan, Sikap Menghindari Risiko, Lokus Kendali, Niat Investasi

\section{LATAR BELAKANG}

Niat berinvestasi mulai bertumbuh di kalangan anak muda. Mereka mencari tahu dan mulai berinvestasi. Generasi muda millennial yang diasumsikan boros, tidak bisa mengelola keuangannya dengan baik, gemar belanja online, jalan-jalan, wisata kuliner, minum kopi, dan gonta-ganti gadget, ternyata juga memikirkan investasi. Muncul fenomena dari The Harris Poll tahun 2018, bahwa 92\% dari millennial sudah suka menabung. Bahkan satu per tiga di antaranya sudah melakukan investasi di luar rencana pensiun yang akan disiapkan. $70 \%$ dari millennial sudah mengetahui cara berinvestasi. The Indonesia Capital Market Institute (TICMI) menemukan hal yang lebih mengejutkan lagi, $61,76 \%$ dari 168 responden millennial telah menerapkan pengelolaan keuangan dengan investasi.

Pilihan investasi generasi millennial yang paling tinggi adalah $54,41 \%$ di pasar modal, dan sisanya di produk perbankan dan sektor riil. Dari $54,41 \%$ hal paling banyak pilihan produk investasi millennial sebesar $(80,88 \%)$ jatuh kepada saham, lalu disusul $16,18 \%$ oleh reksa dana, $1,47 \%$ oleh obligasi, dan yang terakhir $1,47 \%$ untuk produk investasi lainnya.

Dari data itu tampak niat investasi pada saham di kalangan millennial tinggi. Berdasarkan data Kustodian Sentral Efek Indonesia (KSEI), generasi millennial yang 
kebanyakan dari kalangan mahasiswa berusia 21-30 tahun mendominasi investor ritel di pasar modal Indonesia pada akhir tahun 2018.

Yang menakjubkan jumlah investor millennial tahun 2018 meningkat signifikan. Di tahun 2017 lalu persentase investor millennial baru mencapai 26,2 persen atau kurang lebih 288.000 orang dari total investor pasar modal yang berjumlah 1,1 juta investor. Untuk tahun 2018 jumlah investor millennial meningkat menjadi 635.000 orang, secara persentase juga meningkat menjadi $39,72 \%$ berdasarkan data Kustodian Sentral Efek Indonesia (KSEI). (Elisa Valenta dalam Beritagar.id, 2018).

Mengamati tren tersebut, timbul pertanyaan apa sebenarnya faktor yang menyebabkan generasi millennial berinvestasi ke pasar modal? Dari penelitian terdahulu ada tiga faktor penting yang bisa diperhatikan: Pertama, generasi millennial membiasakan diri untuk dapat mengontrol sikap keuangan (financial attitudes) mereka sejak muda.

Dengan menyisihkan uang mereka untuk ditabung dan digunakan untuk hal yang bermanfaat, bukan untuk sekedar berbelanja dan bersenang-senang, maka mereka dapat menyadari bahwa semakin tua mereka akan sulit menyisihkan uang untuk ditabung karena kebutuhan dan tanggung jawab akan menumpuk, sehingga mereka membutuhkan investasi yang dapat dinikmati hasilnya ketika mereka tua nanti.

Menurut Robillard (2018), meskipun sebagian besar millennial mungkin belum memiliki jenis aset yang banyak seperti Mark Zuckerberg, namun millennial pasti suatu hari nanti bisa. $14,7 \%$ dari millennial yang memiliki aset lebih dari $\$ 2$ juta, satu dari lima telah cukup menabung dalam rekening non-pensiun untuk bertahan setidaknya tiga hingga lima bulan, dan enam dari sepuluh berharap menjadi lebih baik secara finansial daripada orang tua mereka. Dari sudut pandang perseptual, tampaknya millennial memiliki keinginan dan kemampuan untuk berinvestasi dan menyimpan kekayaan mereka secara efisien. Layanan yang paling mudah diakses adalah peluang investasi keuangan.

Kedua, generasi millennial yang tergolong masih muda masih bisa mengambil risiko, karena adrenalinnya masih siap untuk menerima risiko. Sebagai anak muda juga masih memiliki kesempatan untuk mencoba lebih. Sedangkan mulai berinvestasi saat usia mendekati masa pensiun, sebaiknya tidak mencoba sesuatu yang terlalu beresiko, karena mungkin tidak bisa menunggu 10 atau 20 tahun lagi sampai pasar saham bangkit kembali. Menurut Formánková et cetera (2019), investor millennial memiliki karakteristik berani mengambil risiko untuk membuat keputusan investasi yang lebih berkelanjutan. Karena mereka percaya bahwa investasi dapat menciptakan perubahan positif, dan menginginkan lebih banyak bukti kinerja, tetapi tetap berkomitmen untuk investasi berkelanjutan. Ini tercermin dalam perilaku investasi mereka, dan sangat relevan untuk bisnis keuangan. Hal ini bertentangan dengan sikap seseorang untuk menghindari risiko (risk aversion), yang biasanya dilakukan oleh orang-orang tua.

Ketiga, lokus kendali (locus of control) untuk memutuskan investasi tentu seseorang perlu mempertimbangkan banyak hal yang dapat dipengaruhi oleh dari dalam dirinya sendiri (internal locus of control) serta dari lingkungan luar (external locus of control). Faktor internal yang dapat dijelaskan dari dalam diri sendiri, seperti seseorang dapat mengambil keputusan berdasarkan dorongan dari dalam diri sendiri. Dan faktor eksternal dapat mengambil keputusan berdasarkan nasib, peluang, keberuntungan, ataupun perilaku orang lain. Kinerja bursa saham yang bagus dan relatif stabil, misalnya membuat banyak generasi milenial tergiur untuk mencoba melakukan sesuatu yang menguntungkan. Menurut Cudmore et cetera (2010), dengan pasar saham yang luas dan informasi yang lebih baik, dan adanya kecenderungan untuk berinvestasi investor muda, tidak diragukan 
lagi ada niat yang lebih besar bagi kaum muda dalam menabung dan berinvestasi untuk masa depan. Ketiga faktor itu menarik peneliti untuk menelitinya, yaitu dengan mengaitkannya.

\section{KAJIAN TEORI}

Berdasarkan Theory of Planned Behavior, faktor utama yang mempengaruhi perilaku individu adalah niat individu terhadap perilaku tersebut. Niat untuk berperilaku sendiri dipengaruhi oleh 3 komponen yaitu attitude, subjective norm, dan perceived behavior control.

Teori selanjutnya merupakan Financial Management Behavior yang berarti kemampuan seseorang dalam merencanakan, menganggarkan, mengelolaan, mengendalikan, mencari serta menyimpan dana keuangan sehari-hari yang dimiliki (Rizkiawati \& Asandimitra, 2018). Menurut (Dew dan Xiao, 2011), Financial Management Behavior dapat dilihat dari 4 hal, yaitu consumption, cash flow management, saving and investment, dan credit management. Penelitian ini berfokus pada saving and investment, yakni niat investasi generasi milenial di pasar modal.

Variabel dependen dalam penelitian ini merupakan Investment Intention yang berarti niat untuk komitmen menggunakan sejumlah uang untuk investasi saham. Sedangkan terdapat 3 variabel independen dalam penelitian ini, yang pertama Financial Attitudes merupakan pengalokasian penghasilan untuk kebutuhan atau merencanakan alokasi keuangan hidupnya dan investasi, yang kedua Risk Aversion merupakan sikap yang cenderung menghindari risiko dalam setiap keberanian mengambil risiko, dan variabel terakhir Locus of Control merupakan pandangan seseorang terhadap masalah hidupnya, yang terbagi menjadi external dan internal.

\section{Kutipan Sumber Acuan}

Investment intention merupakan sebuah konsep untuk menggambarkan berapa banyak individu yang berniat berinvestasi dalam alternative investasi apapun (Aydemir \& Aren, 2017). Financial attitudes merupakan bagaimana seseorang akan menghabiskan, menyimpan, mengakumulasi, atau bahkan menghabiskan uangnya (Nusron, Wahidiyah, \& Budiarto, 2018). Risk aversion merupakan sikap yang mencerminkan pada tingkat mana seseorang menghindari mengambil risiko secara umum dalam hidupnya (Aydemir \& Aren, 2017).

Locus of control merupakan kecenderungan umum seseorang untuk merasakan kontrol, atau tidak adanya, di berbagai situasi. Sejauh mana seseorang mengaitkan hasil yang dinilai dengan keadaan internal atau eksternal. Internal locus of control percaya pada kekuatan keputusan dan perilaku mereka sedniri untuk mempngaruhi peristiwa kehidupan dan menentukan masa depan mereka sendiri. External locus of control memandang peristiwa kehidupan sebagai pengaruh faktor lingkungan di luar kendali seseorang, seperti keberuntungan, nasib, atau yang kuat lainnya (Liew, 2013).

\section{METODOLOGI}

Desain penelitian ini adalah penelitian kausal dengan metode cross sectional design dengan populasi seluruh generasi milenial di Indonesia yang berusia 19 tahun hingga 39 tahun, lalu diambil sampel mahasiswa Fakultas Ekonomi dan Bisnis Universitas Tarumanagara atas sejumlah 190 responden. Metode pengambilan sampel dalam penelitian 
ini adalah metode nonprobability sampling dengan teknik purposive sampling dengan menyebarkan kuesioner. Indikator yang digunakan dalam penelitian ini diadaptasi dari (Philmore Alleyne \& Tracey Broome, 2011) serta (Dinç Aydemir dan Aren, 2017) dengan menggunakan Skala Likert (skala ordinal) lima poin dengan 1 menunjukkan "sangat tidak setuju" dan 5 menunjukkan "sangat setuju" untuk variabel Financial Attitudes, Risk Aversion, Locus of Control dan Investment Intention. Besarnya signifikansi dalam penelitian ini sebesar 5\%. Pengumpulan data pada penelitian ini dengan pembagian kuesioner secara online dengan menggunakan google form dan analisis dengan menggunakan structure equation modeling (SEM) dengan bantuan program SmartPLS 3.2.8.

\section{Hasil Uji Statistik}

Berdasarkan hasil uji convergent validity, discriminant validity dan uji t-stat indikator dengan syarat Average Variance Extracted (AVE) > 0,5 dan nilai loading factor $\geq 0.5$ sehingga lolos validitas konvergen (Kwong \& Wong, 2013), cross loading masingmasing indikator pada variabelnya > dibanding variabel lain dan fornell-larcker kriterianya adalah nilai AVE > dari korelasi yang terjadi sehingga lolos validitas diskriminan (Chin, 1998), serta nilai t-stat $>1.96$. Total terdapat 1 dari 23 indikator dikeluarkan karena tidak memenuhi kriteria (LOC4) dan 22 indikator dipertahankan dalam penelitian.

Nilai R-square diperoleh sebesar 0.647 yang berarti sebesar $64,7 \%$ variabel investment intention dapat dijelaskan melalui variabel independen dalam penelitian ini, dan sisanya sebesar 35,3\% dijelaskan oleh variabel-variabel lain di luar dari penelitian ini.

Berdasarkan penelitian path coefficients, maka variabel financial attitudes dan locus of control mempengaruhi positif dan signifikan terhadap investment intention, sedangkan variabel risk aversion mempengaruhi negatif dan signifikan terhadap investment intention, sehingga didapatkan persamaan $\mathrm{II}=0,252 \mathrm{FA}+0,635 \mathrm{LOC}-0,105 \mathrm{RA}$. Serta ketiga hipotesis dalam penelitian ini tidak ditolak (diterima).

\section{DISKUSI}

Hasil pada penelitian ini menunjukkan bahwa financial attitudes memiliki pengaruh positif signifikan terhadap investment intention. Hal ini menunjukkan bahwa subjek penelitian mengakui adanya pengaruh sikap seseorang dalam menyikapi permasalahan keuangan terhadap niat seseorang untuk berinvestasi di pasar modal, terutama oleh mahasiswa yang tergolong generasi millennial. Penelitian ini dilakukan terhadap mahasiswa yang aktif di Fakultas Ekonomi dan Bisnis Universitas Tarumanagara Jakarta dan berusia tergolong generasi millennial, sehingga dapat diasumsikan bahwa mereka memiliki pengetahuan di bidang ekonomi yang cukup, terutama tentang pasar modal, karena mereka sudah mendapatkan pelajaran tentang investasi (seperti pengetahuan pasar modal, manajemen investasi, dan lainnya), dan perkembangan perekonomian saat ini, sehingga masih fresh dan dapat membandingkan antara materi yang didapatkan di pelatihan dengan teori di bangku kuliah dan praktek nyatanya untuk mulai berinvestasi di pasar modal.

Pada pengukuran financial attitudes, indikator yang memiliki pengaruh paling besar adalah FA3, "Saya merasa menabung merupakan hal yang penting." Hasil ini menunjukkan bahwa mahasiswa mengetahui pentingnya pengalokasian keuangan terhadap menabung sebagai salah satu sikap keuangan untuk memenuhi kebutuhan hidupnya dan 
menyakini bahwa menabung dalam bentuk berinvestasi di pasar modal (saham) dapat memberikan return yang besar. Sehingga dapat disimpulkan bahwa semakin tinggi kesadaran seseorang akan pentingnya menabung, maka semakin tinggi pula niat investasi seseorang pada instrumen investasi saham di pasar modal.

Hasil penelitian ini sesuai dengan hasil penelitian-penelitian sebelumnya yang telah dilakukan oleh Alleyne \& Broome (2011) yang menyatakan bahwa financial attitudes berpengaruh positif terhadap investment intention. Hasil penelitian yang sama juga dengan Akhtar \& Das (2017) dan Wouwe (2018) menyatakan bahwa financial attitudes berpengaruh positif signifikan terhadap investment intention.

Hasil pada penelitian ini menunjukkan bahwa risk aversion memiliki pengaruh negatif signifikan terhadap investment intention. Hal ini menunjukkan bahwa subjek penelitian mengakui adanya pengaruh sikap menghindari risiko dalam setiap tindakan seseorang terhadap niat seseorang untuk berinvestasi di pasar modal, terutama oleh mahasiswa yang tergolong generasi millennial. Penelitian ini dilakukan terhadap mahasiswa yang aktif di Fakultas Ekonomi dan Bisnis Universitas Tarumanagara Jakarta dan berusia tergolong generasi millennial, sehingga dapat diasumsikan bahwa mereka memiliki pengetahuan di bidang ekonomi yang cukup, terutama tentang pasar modal, karena mereka sudah mendapatkan pelajaran tentang investasi (seperti pengetahuan pasar modal, manajemen investasi, dan lainnya), dan perkembangan perekonomian saat ini, sehingga masih fresh dan dapat membandingkan antara materi yang didapatkan di pelatihan dengan teori di bangku kuliah dan praktek nyatanya untuk mulai berinvestasi di pasar modal.

Pada pengukuran risk aversion, indikator yang memiliki pengaruh paling besar adalah RA4, "Saya lebih memilih cara yang aman daripada menyesal." Hasil ini menunjukkan bahwa mahasiswa tidak setuju untuk menghindari risiko dan menyakini tindakan mengambil sesuatu yang berisiko seperti berinvestasi di pasar modal (saham) dapat memberikan return yang besar. Sehingga dapat disimpulkan bahwa semakin tinggi sikap seseorang untuk menghindari risiko, maka semakin rendah pula niat investasi seseorang pada instrumen investasi saham di pasar modal.

Hasil penelitian ini sesuai dengan hasil penelitian-penelitian sebelumnya yang telah dilakukan oleh Aren \& Aydemir (2015) yang menyatakan bahwa risk aversion berpengaruh negatif terhadap investment intention. Hasil penelitian yang sama juga dengan Aydemir \& Aren (2017) yang menyatakan bahwa risk aversion berpengaruh negatif signifikan terhadap investment intention.

Hasil pada penelitian ini menunjukkan bahwa locus of control memiliki pengaruh positif signifikan terhadap investment intention. Hal ini menunjukkan bahwa subjek penelitian mengakui adanya pandangan dirinya pada sumber penyebab masalah hidupnya terhadap niat seseorang untuk berinvestasi di pasar modal, terutama oleh mahasiswa yang tergolong generasi millennial. Penelitian ini dilakukan terhadap mahasiswa yang aktif di Fakultas Ekonomi dan Bisnis Universitas Tarumanagara Jakarta dan berusia tergolong generasi millennial, sehingga dapat diasumsikan bahwa mereka memiliki pengetahuan di bidang ekonomi yang cukup, terutama tentang pasar modal, karena mereka sudah mendapatkan pelajaran tentang investasi (seperti pengetahuan pasar modal, manajemen investasi, dan lainnya), dan perkembangan perekonomian saat ini, sehingga masih fresh dan dapat membandingkan antara materi yang didapatkan di pelatihan dengan teori di bangku kuliah dan praktek nyatanya untuk mulai berinvestasi di pasar modal. 
Pada pengukuran locus of control, indikator yang memiliki pengaruh paling besar adalah LOC3, "Saya dapat melakukan apapun sesuai dengan situasi dan kondisi tertentu." Hasil ini menunjukkan bahwa mahasiswa mengetahui apapun yang terjadi pada dirinya disebabkan dari pengaruh lingkungan luar (external locus of control) dan menyakini bahwa dengan melakukan investasi di pasar modal (saham) sepenuhnya dipengaruhi oleh faktor eksternal seperti kondisi ekonomi, politik, stabilitas negara, dan lainnya yang tidak dapat dikendalikan oleh diri sendiri. Sehingga dapat disimpulkan bahwa seseorang yang memiliki pengendalian diri yang dipengaruhi faktor eksternal dalam hidupnya sendiri, maka semakin tinggi pula niat investasi seseorang pada instrumen investasi saham di pasar modal.

Hasil penelitian ini sesuai dengan hasil penelitian-penelitian sebelumnya yang telah dilakukan oleh Aydemir \& Aren (2017) yang menyatakan bahwa locus of control berpengaruh positif terhadap investment intention. Hasil penelitian yang sama juga dilakukan oleh Abdillah, Sari, \& Hendrawaty (2019) bahwa locus of control memiliki pengaruh yang positif terhadap investment intention.

\section{PENUTUP}

Hipotesis pertama diterima bahwa terdapat pengaruh positif signifikan financial attitudes terhadap investment intention pada mahasiswa yang aktif di Fakultas Ekonomi dan Bisnis Universitas Tarumanagara Jakarta, sehingga diharapkan pemerintah dan lembaga pendidikan (seperti: universitas) dapat mengembangkan edukasi investasi, seperti menambah lebih banyak mata kuliah mengenai investasi, agar mahasiswa lebih tertarik menggunakan uangnya untuk berinvestasi dari pada dihambur-hamburkan, dan mahasiswa bisa akrab dengan dunia investasi terutama pasar modal.

Hipotesis kedua diterima bahwa terdapat pengaruh negatif signifikan risk aversion terhadap investment intention pada mahasiswa yang aktif di Fakultas Ekonomi dan Bisnis Universitas Tarumanagara Jakarta, maka untuk kedepannya pemerintah dan lembaga pendidikan (seperti: Universitas) dapat sering mengadakan seminar dan pelatihan investasi tentang bagaimana syarat serta langkah melakukan investasi di pasar modal, sehingga mahasiswa mengerti risiko yang dihadapi dengan berinvestasi, agar dapat menghindari atau meminimalisir risiko.

Hipotesis ketiga diterima bahwa terdapat pengaruh positif signifikan locus of control terhadap investment intention pada mahasiswa yang aktif di Fakultas Ekonomi dan Bisnis Universitas Tarumanagara Jakarta. Locus of control lebih ke eksternal (lingkungan luar) berdasarkan hasil jawaban responden kuesioner, sehingga disarankan untuk pemerintah dan lembaga pendidikan (seperti: Universitas) dapat memberikan rangsangan kepada mahasiswa untuk berinvestasi di pasar modal, seperti mengadakan seminar dan pelatihan khusus tentang pasar modal, sehingga mahasiswa mendapatkan pengetahuan dan kemampuan lebih tentang pasar modal, agar dapat merasa lebih yakin dan tertarik untuk terjun ke dalam pasar modal.

\section{DAFTAR PUSTAKA}

Abdillah, W., \& Jogiyanto, H. M. (2015). Partial Least Square, Alternative Structural Equation Modeling (SEM) in Business Research. Yogyakarta: Andi. 
Abdillah, W., Sari, R. P., \& Hendrawaty, E. (2019). Understanding Determinants of Individual Intention to Invest in Digital Risky Investment. Jurnal Dinamika Manajemen, 10(1), 124-137.

Ajzen, I. (1991). Theory of Planned Behavior. Organizational Human Behavior and Human Decission Processes. 50, 179-211.

Akhtar, F., \& Das, N. (2017). Predictors of investment intention in Indian stock markets. International Journal of Bank Marketing, 37(1), 97-119.

Aldin, I. U. (2018). Investor Milenial Semakin Mendominasi Pasar Modal. https://katadata.co.id/berita/2018/12/27/investor-milenial-semakin-mendominasipasar-modal

Ali, A. (2011). Predicting Individual Investors' Intention to Invest: An Experimental Analysis of Attutude as Mediator. International Journal of Economics and Management Enginerring, 5(2).

Ali, S., Kasim, K., \& Zani, R. M. (2015). Factors Influencing Investors' Behavior in Islamic Unit Trust: An Application of Theory of Planned Behavior. Journal of Islamic Economics Banking and Finance, 10, 183-201.

Alleyne, P., \& Broome, T. (2011). Using the Theory of Planned Behaviour and Risk Propensity to Measure Investment Intentions among Future Investors. Journal of Eastern Caribbean Studies, 36(1), 1-20.

Amin, H. (2016). Willingness to Open Islamic Banking Gold Investment Account. Journal of Internet Banking and Commerce, 21(1), 1-17.

Aren, S., \& Aydemir, S., D. (2015). The Moderation of Financial Literacy on the Relationship Between Individual Factors and Risky Investment Intention. International Business Research, 8(6), 17-28.

Aydemir, S., D. \& Aren, S. (2017). Do the effects of individual factors on financial risktaking behavior diversify with financial literacy?. Kybernetes, 46(10), 1706-1734.

Azuar Juliandi, D. 2014. Metodologi Penelitian Bisnis, Konsep dan Aplikasi. Medan: UMSU PRESS

Badan Pusat Statistik. (2018). Kementerian Perindustrian Republik Indonesia. http://www.kemenperin.go.id/download/18450

Budiati, I., Susianto, Y., Adi, W P. A., Ayuni, S., Reagan, H. A., Larasaty, P., Setiyawati, N., Pratiwi, A. I., \& Saputri, V. G. (2018). Statistik Gender Tematik: Profil Generasi Milenial Indonesia. Jakarta: Kementerian Pemberdayaan Perempuan dan Perlindungan Anak.

Cucinelli, D., Gandolfi, G., \& Soana, M. G. (2016). Customer and Advisor Financial Decisions: the Theory of Planned Behavior Perspective. International Journal of Business and Social Science, 7(12), 80-92.

Dew, J., \& Xiao, J. J. (2013). The Financial Management Behavior Scale: Development and Validation. Journal of Financial Counseling and Planning, 22(1), 43-59.

East, R. (1993). Investment decisions and the theory of planned behaviour. Journal of Economic Psychology, 14 (1993), 337-375.

Ghozali, I. (2008). Structural Equation Modeling: Metode Alternatif dengan Partial Least Square (PLS). Badan Penerbit Universitas Diponegoro.

Gopi, M. dan Ramayah, T. (2007), "Applicability of theory of planned behavior in predicting intention to trade online: Some evidence from a developing country," International Journal of Emerging Markets, Vol. 2 Issue: 4, pp.348- 360. 
Hair, J. F., Hult., G. T. M., Ringle, C. M., \& Sarstedt, M. (2017) A Primer on Partial Least Squares Structural Equation Modeling (PLS-SEM). Sage: Thousand Oaks.

Hair, J. F., Sarstedt, M., \& Ringle, C.M. (2011). Indeed a Silver Bullet. Journal of Marketing Theory and Practice, 19(2), 139-152. DOI:10.2753/mtp10696679190202.

Henseler, J., Ringle, C.M. \& Sinkovics, R.R. (2009). The Use of Partial Least Squares Path Modelling in International Marketing. Advances in International Marketing, 20, 277319. DOI:10.1108/S1474-7979.

Liew, J. R. V. (2013). Locus of Control. In: Gellman M.D., Turner J.R. (eds) Encyclopedia of Behavioral Medicine. Springer, New York, NY

Malhotra, N. K. (2010). Marketing research: An applied approach. Boston: Pearson.

Montag, I., \& Comrey, A. L. (1987). Internality and externality as correlates of involvement in fatal driving accidents. Journal of Applied Psychology, 72, 339-343.

Nursalam (2003). Konsep dan Penerapan Metodologi Penelitian Ilmu Keperawatan Pedoman Skripsi, Tesis dan Instrumen Penelitian Keperawatan. Jakarta : Salemba Medika

Nusron, L. A., Wahidiyah, M., \& Budiarto, D. S. (2018). Antecedent Factors of Financial Management Behavior: An Empirical Research Based on Education. International Conference on Economics, Business and Economic Education, 2018, 437-445.

Rajna, A. (2011). Knowledge, Attitudes, Practice and Satisfaction on Personal Financial Management among the Medical Practitioners in the Public and Private Medical Services in Malaysia (Doctoral Dissertation, Phd Thesis, Universiti Kebangsaan Malaysia).

Rizkiawati, N. L., \& Asandimitra, N. (2018). Pengaruh Demografi, Financial Knowledge, Financial Attitude, Locus Of Control dan Financial Self-Efficacy terhadap Financial Management Behavior Masyarakat Surabaya. Jurnal Ilmu Manajemen, 6(3), 93-107.

Sadiq, M. N., \& Khan, R. A. A. (2018). Financial Literacy, Risk Perception and Investment Intention among Youth in Pakistan. International Journal of Management Sciences and Business Research, 7(5), 85-93.

Sekaran, Uma. 1992. Research Methods for Business: A Skill Building Approach. John Willey \& Sons, Inc., 2nd edition. New York.

Sitinjak, J.R.T., dan Sugiarto. 2006. LISREL. Yogyakarta: Graha Ilmu.

Sondari, M. C., \& Sudarsono, R. (2015). Using Theory of Planned Behavior in Predicting Intention to Invest : Case of Indonesia. International Academic Research Journal of Business and Technology, 1(2), 137-141.

Sukardi. (2004) Metodologi Penelitian Pendidikan: Kompetensi dan Praktiknya. Jakarta : Bumi Aksara.

Susilowati, Y. (2017). Faktor-Faktor Yang Mempengaruhi Minat Mahasiswa Akuntansi Syariah Untuk Berinvestasi Di Pasar Modal Syariah.

Tenehaus, M., Vinzi, V. E., Chatelin, Y., \& Lauro, C. (2005). PLS path modeling. Computational Statistics \& Data Analysis, 48(1), 159-205. doi:10.1016/j.csda.2004.03.005.

Thomas, P. J. (2015). Measuring risk-aversion: The challenge. Journal of the International Measurement Confederation, 79(2016), 285-301.

Tung, L. C. (2011). The Impact of Entrepreneurship Education on Entrepreneurial Intention of Engineering Students. City University of Hongkong: Run Run Shaw Library, 1-282. 
Van Liew J.R. (2013) Locus of Control. In: Gellman M.D., Turner J.R. (eds) Encyclopedia of Behavioral Medicine. Springer, New York, NY

Vimala, B., \& Alamelu, K. (2018). Financial Literacy Perceived Risk Attitudes, and Investment Intentions among Women. Indian Journal of Research, 7(11), 468-470.

Vuk, K., Pifar, A., \& Aleksić, D. (2017). Should I, Would I, Could I: Trust and Risk Influences on Intention to Invest. Dynamic Relationships Management Journal, 6(1), 61-67.

Wahyono, B., Stats, S. M., \& Santosa, D. (2015). Pengaruh Pendidikan Kewirausahaan terhadap Niat Berwirausaha Siswa SMK Negeri 1 Pedan Tahun 2013. Journal of Entrepreneur, 1(1), 1-17.

Wanyoike, D. (2016). Psychological Factors And Investment Decisions Among United States International University Students. A Research Report Submitted to the Chandaria School of Business in Partial Fulfilment of the Requirement for the Degree of Masters of Business Administration (MBA). Spring.

Wouwe, J. P. V. (2018). Private-Sector Investor's Intention and Motivation to Invest in Land Degradation Neutrality. Public Library of Science, 13(12).

Yang, X., et al. (2019). Developing and Validating a Theory-Based Model of Crowdfunding Investment Intention-Perspectives from Social Exchange Theory and Customer Value Perspective. Journal of Sustainability, 11(2525), 1-18. 